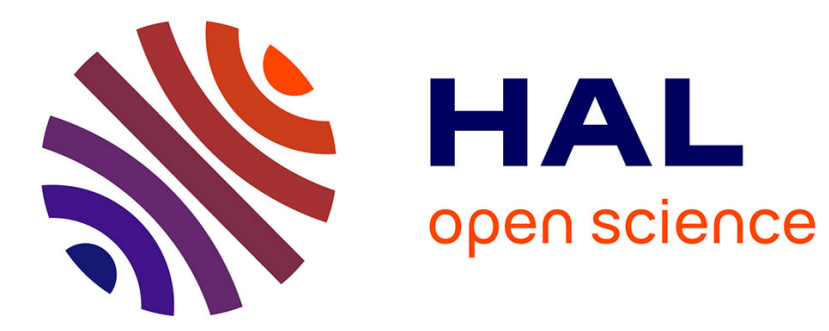

\title{
Left-behind children and return migration in China
}

\author{
Sylvie Démurger, Hui Xu
}

\section{To cite this version:}

Sylvie Démurger, Hui Xu. Left-behind children and return migration in China. IZA Journal of Migration, 2015, 4 (10), 21 p. 10.1186/s40176-015-0035-x . halshs-01179088

\section{HAL Id: halshs-01179088 \\ https://shs.hal.science/halshs-01179088}

Submitted on 22 Jul 2015

HAL is a multi-disciplinary open access archive for the deposit and dissemination of scientific research documents, whether they are published or not. The documents may come from teaching and research institutions in France or abroad, or from public or private research centers.
L'archive ouverte pluridisciplinaire HAL, est destinée au dépôt et à la diffusion de documents scientifiques de niveau recherche, publiés ou non, émanant des établissements d'enseignement et de recherche français ou étrangers, des laboratoires publics ou privés. 


\section{Left-behind children and return migration in China}

Sylvie Démurger ${ }^{1,2,3^{*}}$ and Hui $\mathrm{Xu} \mathrm{u}^{4,2}$

\author{
* Correspondence: \\ demurger@gate.cnrs.fr \\ ${ }^{1}$ Université de Lyon, Lyon F-69007، \\ France \\ ${ }^{2}$ CNRS, GATE Lyon St Etienne, 93, \\ chemin des Mouilles Ecully, Lyon \\ F-69130, France \\ Full list of author information is \\ available at the end of the article
}

\begin{abstract}
This paper examines how left-behind children influence migration duration in China. We first present a simple illustrative model that incorporates economic and non-economic motives to migration duration. Using individual data from a survey carried out in Wuwei county (Anhui province) in 2008, we find that migrant parents of children in primary school tend to delay their return, a result we interpret as illustrating the need for migrant parents to accumulate money for their offspring's education. In contrast, parental time appears substitutable by coresiding grandparents who contribute to delay the parents' return, especially mothers, when they have children below the age of 12 .

JEL classification: J61, J13, C41, 053

Keywords: Return migration; Left-behind children; Discrete-time duration analysis; China
\end{abstract}

\section{Introduction}

Economic development is often combined with the transfer of a large proportion of workers from the rural-based traditional agricultural sector to the urban industrial sector. China has been witnessing such a massive internal labour transfer since the mid80s. The latest official figures from the Sixth National Population Census released in April 2011 estimate the total number of rural migrant workers to be 153 million in $2010^{1}$. Such large-scale internal migration results from a series of institutional and structural changes along with rapid industrialisation. Before the reforms started in 1978, labour mobility was strictly controlled. Since then, the government policy has loosened, moving from permitting rural labour mobility, to guiding rural labour mobility and then encouraging rural labour mobility. Thanks to the relaxation of various regulations, people are, in principle, free to move to places they want and to live and work in cities as long as they want (Fan et al., 2011).

However, while labour mobility in China has dramatically increased over time, temporary migration dominates population movements that are shaped by the strong institutional constraints imposed by the household registration system (Hukou). Formally established in 1958, this system requires every Chinese citizen to be registered according to her place of permanent residence and occupation (agricultural versus nonagricultural $)^{2}$. It confers different legal rights to residents. In villages, residents are given rights to land for farming and housing, while in cities residents are given access to urban

\section{Springer}


jobs and rights to a package of welfare and social benefits. Though the system has been partially reformed, access to public services remains deeply tied to the household registration place, to the disadvantage of migrants. This is notably the case for children's education. Because the education budget for the nine-year compulsory education in China is allocated through local governments and is not transferable, urban schools with a limited education budget are reluctant to accept rural migrant children unless their parents compensate for the additional cost. Hence, although rural migrant children are not officially denied access to the urban public school system, parents are requested to pay "education endorsement fees" (jiaoyu zanzhu fei) for children attending school in places other than their place of household registration, and the amount of such fees can be prohibitive for poor migrant families (Lai and Chen, 2010). At the non-compulsory senior high school level, additional registration place-based constraints also apply because the education policy requires students to take the university/college entrance examination in their hukou registration area ${ }^{3}$. A direct consequence of such administrative and financial barriers is that migrant's children are often left behind in rural home regions as long as they are enrolled in the education system and are looked after either by one parent or by grandparents or relatives.

Because increasingly more people are involved in internal migration, the number of "left-behind" children (liushou ertong) is also increasing dramatically. According to data from the Sixth National Population Census, there were a total of 61 million left-behind children in rural China in 2010, of which approximately 43 million were below the age of 14 (UNICEF, 2014). Together with another 35.8 million living with their migrant parents in cities, the two groups account for $38 \%$ of all children in China. Compared with 2000, the number of rural left-behind children in 2010 is triple (UNICEF, 2014). Data gathered as part of the Rural-Urban Migration in China and Indonesia (RUMiCI) project confirm that many migrant children grow up away from their parents: in 2007, approximately $60 \%$ of the migrant children aged 16 and below were left behind in the rural hometown (Gong et al., 2008).

As argued by Rossi (2008), leaving children behind is a source of a potentially high "social cost of migration", although migration may also confer benefits to the leftbehind family through remittances that ease budget constraints and thereby increase health and education opportunities ${ }^{4}$. Migration can affect children in various dimensions. Children who grow up either with a single parent or with grandparents or relatives may suffer from a lack of parental care that adversely affects their educational outcomes (Giannelli and Mangiavacchi, 2010; McKenzie and Rapoport, 2011). Moreover, the break-up of the family unit can create material and psychological insecurity that affects the well-being of children left behind. For China, there is small body of literature that examines the well-being of left-behind children by focusing on different facets of living arrangement outcomes, such as school performance and health condition. Mixed results have been found regarding the effect of migration on children's school performance. In their early study based on survey data from 36 primary schools in Shaanxi province in 2006, Chen et al. (2009) do not find evidence of any negative impact of migration on school performance. In contrast, a number of more recent papers offer evidence of a net negative impact of parental migration on education outcomes of children who are left behind. For instance, studies that use data from the China Health and Nutrition Survey (CHNS) show that migrant children are worse off 
in terms of school enrolment and years of schooling compared with children whose parents do not migrate (Lee, 2011; Lu, 2012). The lag in educational progress of the children who stay behind in rural areas is corroborated by Meyerhoefer and Chen (2011) on data from the 1995 China Living Standards Survey (CLSS) in 2 north eastern provinces (Hebei and Liaoning). Drawing on data collected in 2000 in 6 provinces representative of China, Wang (2014) also confirms the detrimental impact of parental migration on children's school enrolment and finds that the negative effect is larger for boys than for girls. The adverse effect of parental migration is found to start early in the educational process for boys and to persist over time, whereas for girls, it is significant at the secondary school level only. A negative impact of parental migration is also found on children's school performance and cognitive development (Zhang et al., 2014; Zhao et al., 2014; Zhou et al., 2014). Zhang et al. (2014) study grade 3 to grade 5 pupils in a county of Hunan province and find significant negative impacts of being leftbehind by both parents on children's cognitive development (measured by Chinese and mathematics test scores), whereas the impact of being left-behind by one parent is insignificant. Similar findings are reported by Zhou et al. (2014) on data from children staying behind in Anhui and Jiangxi provinces. Finally, drawing on survey data on grade 4 and grade 5 pupils collected in 2009 in Ningxia and Qinghai, Zhao et al. (2014) find that the negative impact of having a migrant parent on a child's math score is larger with a migrant mother than with a migrant father.

With respect to health outcomes, Gao et al. (2010) find that parental migration is a risky factor for unhealthy behaviours amongst adolescent school children in rural China. In a recent study using the CHNS panel data from 1997 to 2006, Mu and de Brauw (2015) offer evidence that parental migration has no significant impact on the height of young children (aged under 5 in the initial years of the panel) but that it improves their weight. Finally, Kong and Meng (2010) find that children of migrants (either left behind or in cities) are less likely to have good education and health outcomes compared with rural non-migrant children and urban children.

Because family ties in Chinese society remain very strong, there are good reasons to expect that concerns about the welfare of left-behind family members may affect migration (and return) decisions. Accounting for the social cost motive of leaving behind children in determining the length of rural-urban migration in China is important not only from an academic perspective but also in terms of policy implications. The growing tension over the "migrant labour shortage" that has appeared in China's coastal cities, where booming small and private enterprises have absorbed a large quantity of migrants from western China, is illustrative of the importance of family factors in migration decisions. Moreover, as mentioned above, the hukou system is considered an important cause of the transient nature of migration. Evaluating the role of children in individual's decisions regarding migration duration can thus help to further understand the multidimensional impact of the hukou system on migration.

The overall goal of this paper is to explore the role of children as a motive for return migration in China. We first present a simple illustrative model of migration duration based on Dustmann (2003) that accounts for left-behind children through parents' altruistic behaviour. The discussion also points to the potential differentiated impact of children on return decisions depending on their age and gender. Then, using a unique dataset collected in 2008, we provide an empirical test based on a duration model. We 
estimate the determinants of the length of migration for both on-going migrants with incomplete migration spells and return migrants with complete migration spells.

Our paper contributes to the existing literature in at least two directions. First, although children may be important stakeholders in the migration phenomenon, little attention has been given to children in the analysis of migration decisions in the international migration literature. A few exceptions are Djajic (2008) and Dustmann (2003). In the Chinese context, the dearth of data is an important limit to the study of the interaction between left-behind children and migration duration. To our knowledge, Connelly et al. (2012) is the only work that thoroughly studies the role of children in the migration decisions of Chinese women using data collected in the early 2000s. Complementary to their study, we propose an updated and more comprehensive evaluation of how left-behind children affect the return decision. In particular, we use a recent database that covers a period during which both rural-urban migration and a counter-flow of population back to the countryside increased dramatically, which may enable us to better capture recent changes associated with return migration in China. Based on these data, our analysis also adds to the work of Connelly et al. (2012) by examining the whole migrant population (rather than only women at the age of childbearing) and by analysing both complete and incomplete episodes of migration for the entire individual migration history.

Second, by examining the determinants of the length of migration, this paper also contributes to filling the lack of research on migration duration in China. Although the length of migration is an important indicator of the flow and scale of migration as well as the economic effects on both receiving and sending regions, it has received rather limited attention in the migration literature, including for international migration ${ }^{5}$. For China, the issue has strong political importance because there is a fear that the inability of cities to adequately absorb rural migrants may eventually lead to social unrest.

The paper proceeds as follows. Section 2 describes the study area and provides descriptive statistics on migration duration. Section 3 presents a simple illustrative model. The empirical methodology is described in Section 4, and the determinants of migration duration are discussed in Section 5. Section 6 concludes.

\section{Study area and data description}

The data used in this paper come from a series of rural household interviews conducted in Wuwei county, Anhui province, from September to November 2008. Wuwei county was selected because of its relatively long labour force export history, the county being famous for sending out female domestic service workers since the beginning of the 1980s. According to local official statistics, individuals working outside the county accounted for 43 per cent of the entire county's rural labour force at the end of 2006 (Wuwei County Government, 2007). Together with the large-scale migration, the county is also characterised by a sizable number of left-behind children ${ }^{6}$. Recent data show that in the district of Wuhu, to which Wuwei county belongs, 83,400 of the total 332,000 compulsory education students are left-behind children, accounting for $25 \%$ of the entire student population $^{7}$. In another county of the province, Lujiang county, a comprehensive survey conducted in 2005 and 2006 for 12 middle schools in 9 towns showed that up to 60\% of the student population were left-behind children with one or both parents being migrants the year before the survey (Xu et al., 2007). 
Four towns were chosen for the survey: Gaogou, Liudu, Dougou and Tanggou. Three administrative villages in each town and twenty households on average in each village were randomly selected. A total of 239 households were interviewed, providing information on 969 individuals. Individual information includes personal characteristics, current working position and income. For those having a migration and/or return migration history, their working experience during and after migration was also recorded. A separate administrative village survey was also conducted in each village to collect information about the general economic, geographic and demographic conditions at the locality.

The sample used in this paper is composed of 284 individuals having a migration and/or return migration history, with 125 return migrants and 159 on-going migrants. Return migrants are individuals who are currently residing and working in the county with at least 6 months migration work experience outside the county. These individuals declared having no plan to migrate again. On-going migrants are individuals who are either in cities at the time of the survey ${ }^{8}$ or temporarily returned with a plan to migrate again soon (they are circular migrants). This dataset is unique in that it contains detailed information both on the complete length of migration for each return migrant and the incomplete length of migration for on-going migrants. For return migrants, the length of migration duration is defined as the total cumulated number of years of migration from the year of an individual's first migration up to the year of her last return. For on-going migrants, the length of migration duration is the total cumulated number of years of migration from the year of an individual's first migration until the year of the survey.

Information gathered during the survey provides hints on the importance of the leftbehind children phenomenon in the area and on its possible relation with return decisions. Most school-age children (76.4\%) are found to be living in the local town or village, and only $2.5 \%$ are living with their migrant parents in cities. A small portion (16\%) is living alone in other places outside the county: this is mostly the case for students of above high school level who pursue studies in other regions. Although our data did not directly record the situation for pre-school children (under the age of 6), pre-school children are facing a similar situation of separation from their parents. The survey collected information on the reasons for return migration, with multiple answers allowed. Of all the reasons provided, 25\% were related to children, either to "look after children" or "for children's education".

Table 1 reports summary statistics of migration spells. The mean length of migration for the overall sample is 6.74 years, and 31\% of migrants have experienced more than 8 years of migration ${ }^{10}$. The mean lengths of stay for both on-going and return migrants are fairly close, though slightly longer for the former (6.88 years vs. 6.57 years). The pairwise correlation of the length of migration with the year of migration is negative and significant for both return migrants and on-going migrants: earlier migrants are more likely to have a longer migration duration than more recent migrants ${ }^{11}$.

Table 2 presents descriptive statistics for the overall sample as well as for return migrants and for on-going migrants. The average age of migrants (both return and ongoing) is 34 years and the average education level is 6.8 years. Of the sample, $42 \%$ of migrants are female, $72 \%$ are married with an average migrant household size of 4.7 , and $53 \%$ have a migrant spouse (either return or on-going). In terms of family composition ${ }^{12}$, half the migrants have children under the age of 16,14\% have children aged between 12 
Table 1 Migration spells statistics

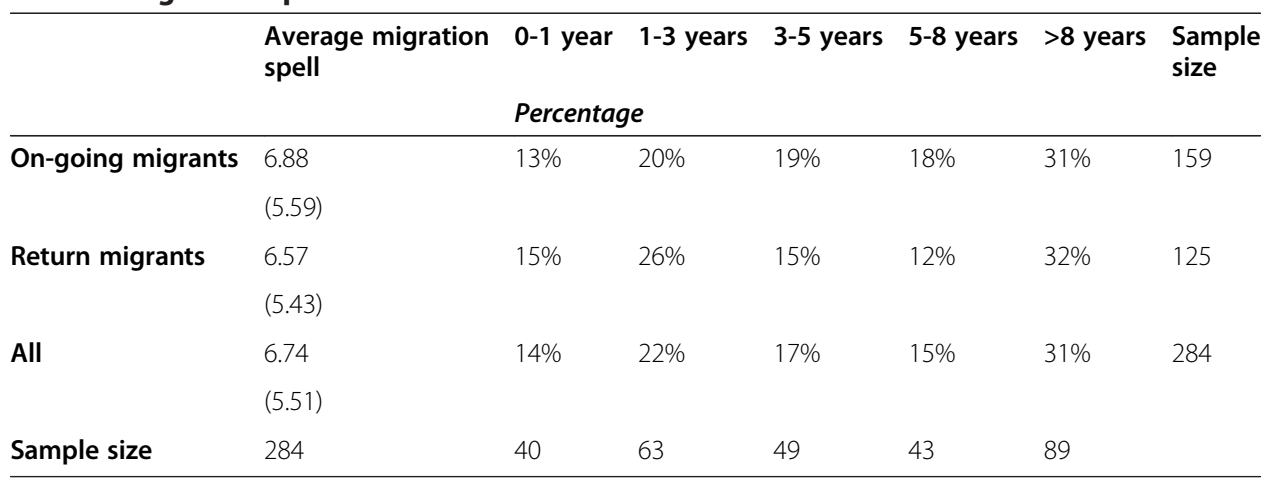

Source: Wuwei 2008 Survey.

Notes: Standard deviation in parenthesis.

and 15, 23\% have children aged between 6 and 11, and 28\% have pre-school children (under the age of 6).

The sub-sample of return migrants is significantly much older (11 years difference), less educated, more likely to be married, and less likely to have household members aged between 55 and 70 at home than the out-migrant population. Interestingly, for their first migration, return migrants migrated on average at an older age than on-going

Table 2 Descriptive statistics

\begin{tabular}{|c|c|c|c|c|}
\hline Mean value or $\%$ & Return migrants & On-going migrants & Mean test & Full sample \\
\hline Age (years) & 40.20 & 29.65 & $* * *$ & 34.29 \\
\hline Age at first migration (years) & 26.37 & 22.29 & $* * *$ & 24.08 \\
\hline Female & 0.416 & 0.415 & NS & 0.415 \\
\hline Married & 0.888 & 0.591 & $* * *$ & 0.722 \\
\hline Education (years) & 5.888 & 7.434 & $* * *$ & 6.754 \\
\hline Household size & 4.256 & 5.006 & $* * *$ & 4.676 \\
\hline Migrant spouse & 0.600 & 0.465 & $* *$ & 0.525 \\
\hline At least a member above 70 & 0.176 & 0.170 & NS & 0.173 \\
\hline At least a member aged 55 to 70 & 0.376 & 0.560 & $* * *$ & 0.479 \\
\hline \multicolumn{5}{|l|}{ Children-related variables } \\
\hline At least one child $(<16)$ & 0.472 & 0.522 & NS & 0.500 \\
\hline At least one child (12-15) & 0.184 & 0.101 & $* *$ & 0.137 \\
\hline Son (12-15) & 0.120 & 0.050 & $* *$ & 0.081 \\
\hline Daughter (12-15) & 0.088 & 0.057 & NS & 0.070 \\
\hline At least one child (6-11) & 0.176 & 0.264 & $* *$ & 0.225 \\
\hline Son (6-11) & 0.080 & 0.201 & $* * *$ & 0.148 \\
\hline Daughter (6-11) & 0.120 & 0.113 & NS & 0.116 \\
\hline At least one child $(<6)$ & 0.216 & 0.321 & $* *$ & 0.275 \\
\hline Son $(<6)$ & 0.120 & 0.151 & NS & 0.137 \\
\hline Daughter $(<6)$ & 0.112 & 0.170 & * & 0.144 \\
\hline Sample size & 125 & 159 & & 284 \\
\hline
\end{tabular}

Source: Wuwei 2008 Survey.

Notes: For return migrants, all children-related variables are computed at the moment of return; for on-going migrants, they are computed at the time of the survey. The mean test column indicates the significance level of mean differences between return migrants and on-going migrants. NS non-significant; ${ }^{*}$ significant at $10 \%$; ${ }^{* *}$ significant at $5 \% ;{ }^{* * *}$ significant at $1 \%$. 
migrants (26 years versus 22 years). As return migrants are older, this gap illustrates the tendency of the younger generation to move to cities at a younger age compared with early migrants. In regard to children-related variables, there are interesting gender differences too. Return migrants are significantly less likely to have a son in primary school at the moment of return than on-going migrants at the time of the survey, but this is not the case for daughters. By contrast, they are more likely to have a son aged 12 to 15 (in junior secondary school) at the moment of return than on-going migrants at the time of the survey, and again, there is no significant difference for daughters.

\section{An illustrative model of return decisions with left-behind children}

Return migration can be considered part of a lifetime utility maximisation plan with a given budget (and liquidity) constraints (Borjas and Bratsberg, 1996). In the international migration literature, the return motives notably include location preferences with a higher marginal utility of consumption in the area of origin (Djajic and Milbourne, 1988), a higher purchasing power of the destination area currency at home (Djajic, 1989; Stark et al., 1997), and higher returns to human capital accumulated in the destination area at home (Dustmann, 2001; Dustmann et al., 2011). However, as highlighted by Dustmann (2003) and Djajic (2008), the decision to return and the optimal time of return can also be influenced by altruistic motives of parents towards their offspring in the household. Hence, the migration behaviour, and the decision to return, may be driven not only by individual life-cycle considerations but also by dynastic motives such as offspring's welfare in the future ${ }^{13}$. Emphasising the family unit rather than the individual migrant makes sense in rural China, where family ties are strong and may be important components in explaining individual decisions. Moreover, such an approach seems the most relevant in a context where migration patterns are shaped by the household registration system (hukou), which does not entitle rural migrants to urban benefits and leaves most children behind. In their study of a sample of migrants living in Beijing, Fan et al. (2011) argue that the desire to be near left-behind children is an important reason for a migrant's return.

The simple model presented below is meant to be illustrative of the conjectured influence of left-behind children on return migration. It builds on Dustmann (2003) and includes a number of alterations to account for specific Chinese features. First, we assume that the parent migrates alone and leaves behind her child. Second, because we are interested in school-aged or pre-school children in the home village, we also assume that the child does not work in the second period. Given these two assumptions, the proposed model captures the situation of a family unit composed of a worker engaged in migration (the parent migrant) and a left-behind child.

We consider two periods. In period 1, the parent works and lives in a city, while her child lives in the countryside and is subsidised by the parent. In period 2, the parent may decide to return or to stay in the city. The parent decides her own and her child's consumption in periods 1 and 2. Because the child is not assumed to work in period 2, the altruism of the parent takes place through income transfer to the child in period 1 and through daily care (in case of return) or income transfer (in case of settlement in city) in period 2. As in Dustmann (2003), the return decision is taken by simply comparing lifetime welfare in the two locations. 
The utility functions of the parent are supposed to take the usual logarithmic form. Period 1's utility function $U^{1}$ is given by:

$$
U^{1}\left(c^{1}, k^{1}\right)=\ln \left(c^{1}\right)+\gamma \ln \left(k^{1}\right)
$$

where $c^{1}$ is the consumption of the migrant parent, $k^{1}$ is the consumption of the leftbehind child, and the parameter $\gamma>0$ is the altruism weight.

Period 2's utility function $U^{2 j}$ depends on the location choice of the migrant, whether settled in the city $(j=M)$ or returned home $(j=R)$, and is given by:

$$
U^{2 j}\left(c^{2 j}, k^{2 j}\right)=\ln \left(c^{2 j} a^{j}\right)+\gamma \ln \left(k^{2 j} b^{j}\right),
$$

where $a^{j}$ and $b^{j}$ are preference parameters. In particular, $a^{R}>a^{M}$ and $b^{R}>b^{M}$ reflect a location preference of the migrant for her home village in terms of both her own consumption $(a)$ and her offspring's consumption (b).

Under the simplifying assumption of no discounting, the total utility function $U$ of the parent can be simply expressed as follows:

$$
U=\ln \left(c^{1}\right)+\gamma \ln \left(k^{1}\right)+(1-h)\left[\ln \left(c^{2 M} a^{M}\right)+\gamma \ln \left(k^{2 M} b^{M}\right)\right]+h\left[\ln \left(c^{2 R} a^{R}\right)+\gamma \ln \left(k^{2 R} b^{R}\right)\right],
$$

where the parameter $h$ stands for the return decision. At $h=1$, the migrant decides to return; at $h=0$, she settles in the city.

The budget constraint of the parent equalises intertemporal income and consumption:

$$
c^{1}+(1-h) c^{2 M}+h c^{2 R}+k^{1}+(1-h) k^{2 M}+h k^{2 R}=y^{1}+(1-h) y^{2 M}+h y^{2 R},
$$

where $y^{1}, y^{2 M}$, and $y^{2 R}$ are the income of the parent in period 1, period 2 in the city, and period 2 at home, respectively.

The return decision of the migrant is given by the maximisation of her utility $U$ with respect to her own consumption in periods 1 and 2 as well as to her left-behind child's consumption in periods 1 and 2 under the budget constraint expressed above for two scenarios: settling in the city $(h=0)$ or returning to the countryside $(h=1)$. The intertemporal utility maximisation leads to the following results. The migrant parent will choose to return if:

$$
2(1+\gamma) \ln \left(\frac{y^{1}+y^{2 R}}{y^{1}+y^{2 M}}\right)+\ln \left(\frac{a^{R}}{a^{M}}\right)+\gamma \ln \left(\frac{b^{R}}{b^{M}}\right)>0
$$

As in Dustmann (2003), the first term illustrates the income impact of return on total utility: as earnings can be assumed to be lower at home $\left(y^{2 R}<y^{2 M}\right)$, the decision to return will entail a loss in utility. The loss in utility is higher for altruistic parents $(\gamma>0)$ because their reduced earnings also affect the child's outcomes. This may be the case, for instance, if the reduced earnings contribute to reduce opportunities for education or health care. This first term captures a standard money income effect. Moreover, if the migrant has no location preference $\left(a^{R}=a^{M}\right.$ and $\left.b^{R}=\mathrm{b}^{M}\right)$, her altruistic behaviour would reinforce the standard income effect towards a decision not to return. The second term shows the influence of the relative location preference of the migrant in terms of her own consumption. If $a^{R}>a^{M}$, her relative preference for her home village may partly compensate the income effect and logically reduce migration duration. The 
third term reflects the parent's perception of the well-being of the left-behind child. If the child is perceived as suffering from parental absence in her daily life, then $b^{R}>\mathrm{b}^{M}$ will give an incentive to the parent to return. This third term captures a time of the parent effect. Assuming no migrant parent location preference in her own consumption $\left(a^{R}=a^{M}\right)$, the decision to return for an altruistic parent simply reduces to a comparison of the loss in utility due to lower income (and, possibly, a reduction in education opportunities) with the gain in utility thanks to a better-off child (through better quality day-to-day care, for instance).

In the vein of Dustmann (2003), this model illustrates the major trade-off a migrant parent faces when deciding to stay or to return: the consumption of the child is multidimensional and the various channels related to money and to parental time may work in opposite directions regarding the decision to return. In addition, the magnitude of each effect may vary with the age of the child: day-to-day care may be particularly valued for young children, while educational opportunities become important when the child is of school age. In a society with a strong tradition of preference for sons ${ }^{13}$, one may further expect that the return-decision outcome is also linked to the gender of the child, although the total child effect may remain ambiguous. Finally, in the Chinese context, an additional feature to consider is the high prevalence of multigenerational coresidence in rural areas and the potentially major role of coresident grandparents in their grandchildren's lives (Zeng and Xie, 2014). Analysing rural data from the China Household Income Project (CHIP) survey 2002, Zeng and Xie (2014) show for instance that the effect of coresident grandparents' education on grandchildren's educational attainment is as large as that of parental education (while this is not the case for noncoresident grandparents). From a survey on migrants living in Beijing, Fan et al. (2011) find evidence that migrants with fewer parents in the home village are more likely to bring their children with them, and they argue that migrants prefer to leave their school-age children behind for easier access to education in the home village when their own parents are available to help. Hence, the presence of coresiding grandparents may attenuate the parental time effect through a (parents-to-grandparents) substitution effect for day-to-day care, and again, the magnitude of the effect may vary with the age of the child, and possibly with the gender of the migrant parent.

In summary, the return decision $(h)$ of a migrant will depend on the expected income gap between the city and the hometown, the migrant's preferences and altruism, her children's characteristics (notably gender and age), and the availability of some parental substitutes (e.g., grandparents). The empirical analysis presented below aims to estimate this reduced-form relationship by focusing on the migrants' length of stay in cities.

\section{Empirical approach}

\section{Framework for duration analysis}

As indicated above, our dataset contains a sample including both on-going outmigrants and return migrants, which allows us to analyse complete and incomplete length of migration. Migration duration data are right-censored by definition because the date of transition out of the state (i.e., returning home) is unknown for on-going migrants. As highlighted by Jenkins (2008), survival (or duration) analysis offers a number of advantages compared with OLS or binary choice models for such data. In 
particular, it is well suited to account for the timing of migration events (including return migration), for censoring in the data, and for incorporating time-varying variables in the estimation.

Because answers about migration duration were given in months, discrete time periods for migration duration are defined in months ${ }^{15}$. Consequently, we use a discrete-time (grouped data) version of the commonly used proportional hazard ( $\mathrm{PH})$ model $^{16}$ developed by Prentice and Gloeckler (1978). Let $T_{i}$ be the discrete random variable representing the uncensored time at which the end of migration occurs. Then, for individual $i$ who stayed in the city for at least $t$ months, the discrete-time hazard rate $\lambda_{i}(t, X)$ conditional on covariates can be defined as follows:

$$
\lambda_{i}(t, X)=\operatorname{Pr}\left[T_{i}=t / T_{i} \geq t, X_{i t}\right]
$$

This equation gives the conditional probability of individual $i$ 's migration ending at time $t$, given that it has not ended yet. We consider a complementary log-log specification for the hazard function, which gives:

$$
\lambda_{i}(t, X)=1-\exp \left[-\exp \left(\beta^{\prime} X_{i}(t)+\gamma(t)\right)\right]
$$

As shown by Prentice and Gloeckler (1978), this model is a discrete-time analogue to the continuous-time Cox proportional hazard model. $\gamma(t)$, which depends on $t$ alone, is a transformation of the baseline hazard common to all individuals. We assume a duration dependence pattern analogous to that in the continuous-time Weibull model ${ }^{17}$ by entering the $\log$ of $t$ as a covariate. $\exp \left(\beta^{\prime} X_{i}(\mathrm{t})\right)$ is a person-specific non-negative function of covariate $X$, which scales the baseline hazard function common to all persons.

An important issue in duration models is unobserved heterogeneity. Ignoring unobserved heterogeneity that arises when unobserved factors influence duration can lead to a severe bias in the estimates of the covariate effects (Lancaster, 1990). Consequently, one could obtain an underestimate of the true proportionate response of the hazard if the unobserved heterogeneity is not captured because of potential omitted variables or measurement errors (Jenkins, 2008). We account for unobserved heterogeneity by incorporating a Gamma distributed random variable with unit mean and finite variance, as suggested by Meyer (1990).

The covariates that enter the vector $X$ include individual characteristics, such as age ${ }^{18}$, gender, education and marriage, and individual migration experience measured by an occupational dummy variable that equals one if the migrant is a wage-worker during the last/current job in the city and zero otherwise. Destination and hometown characteristics are also measured, respectively, by the size of the destination city and the logarithm of the town's average rural per capita annual net income between 2004 and 2008. We also control for household characteristics that may influence the decision to return. Four variables are considered: the household size, the migration status of the spouse, and two dummy variables for having a household member aged, respectively, between 55 and 70, and above 70. We distinguish these two age groups for the elderly in order to get a clearer view of the effect of grandparents. As mentioned above, grandparents in Chinese society play a potentially prominent role in their grandchildren's care. In the meantime, elders also count as dependents who need to be taken care of. As a tradition in Chinese society, supporting old parents is an important responsibility for children when they grow up. If this is the case, then having elderly at home may 
also be an obstacle for children to choose to work far away. Since the average age of migrants in our sample is 34 years old, the age of their parents can confidently be assumed to be around their late 50s or early 60s, and the elderly aged above 70 are more likely to be the great grandparents of the migrant children.

Finally, to assess how the presence of children by age and by gender affects the parent's length of stay in the city, we use a set of children-related variables for each individual at the time of return measured by dummy variables. We define children as family members who are below the age of 16 . We then further distinguish children from different age-groups (children between 12 and 15, children between 6 and 11, and pre-school children) and by gender.

\section{Endogeneity concerns}

One difficulty in investigating the role of children in the return migration decision is that there are potential identification concerns. First, migration plans and fertility may be simultaneous decisions. Second, unobserved factors that are related to fertility may simultaneously affect return plans. Unfortunately, our cross-section database does not allow us to adequately address the potential endogeneity bias from a statistical point of view. However, we argue that in the case of China, there are good reasons to believe that the implied bias should not be too strong because the fertility decision is not fully private and free as it is in other countries. That said, we also acknowledge that we cannot fully rule out potential identification issues and that the implied biases should be kept in mind when interpreting the coefficients.

China provides an interesting case regarding fertility that is both controlled and low. The one-child policy introduced in 1979 to control population growth, which was deemed to be a serious threat to economic development, resulted in a significant change in the family structure through its strong impact on the timing of first birth and on the likelihood of higher-order births. Restrictions on family size and on the timing of marriage and child bearing that were imposed under the policy led to a sharp decrease in the total fertility rate from 2.8 in 1979 to 1.8 in 2001 (Festini and de Martino, 2004). As documented in McElroy and Yang (2000), although the policy is more liberal in rural than urban areas, a second child, at most, can be approved by local authorities while a third child remains prohibited (for Han people).

The local enforcement of the one-child policy in Wuwei county can be seen from data on the number of children per household. In our sample (including both migrant and non-migrant households), the average size of the household is 4.07. On average, households have 0.64 children below the age of 16 ; $51 \%$ have no child below 16 ; $35 \%$ have 1 child; $13 \%$ have 2 children; and $1 \%$ have 3 children. The proportions are similar when the sample is restricted to women aged between 20 and 50. Moreover, a comparison between non-migrants and migrants (either returned or on-going) does not reveal any significant difference in the number of children between the two groups, which indicates no strong relationship between migration and fertility behaviour, at least in the area under study.

In addition to the low level of fertility, another feature worth emphasising here is that the one-child policy entails controls that make the fertility decision not free at the individual or family level, even for the timing of the first birth. Michelson's (2010) 
description provides a clear overview of the control put on fertility in rural areas: "The performance of local cadres is evaluated to an important measure by their success in meeting birth targets. To keep local fertility levels within these fixed targets, couples wishing to have a child are required to apply for a birth permit. Birth permits are issued only to applicants who satisfy policy conditions-if the local birth quota for the year has not been reached. In other words, every birth is supposed to be authorised, or on the plan" (p. 192). Local family planning authorities are responsible for the enforcement of the policy in the form of punishments and fines for couples who do not comply with the family planning. Evidence has also been reported of more draconian measures being employed, such as forced abortion or sterilisation by the local family planning authorities (Hardee-Cleaveland and Banister, 1988).

\section{Migrants' length of stay in cities: a duration analysis}

Figure 1 depicts non-parametric Kaplan-Meier estimates of the survival function. It clearly highlights negative duration dependence: the probability that migration ends shortly increases with the length of migration. The hazards are high at the beginning of a spell and then decline monotonically. The median survival rate (i.e., stay in cities) is approximately 132 to 144 months (11-12 years). When the migration spell reaches more than 252 months (i.e., approximately 21 years), the overall survival rate finally stabilises at a low level of approximately $12 \%{ }^{19}$, suggesting that $12 \%$ of the migrant population tends to settle permanently in cities.

Table 3 reports estimation results for the discrete-time proportional hazard model with various sets of covariates. Model 1 is the baseline model where a dummy for having at least one child under the age of 16 in the household is introduced. Model 2 includes a set of control variables by age groups: children under the age of 6 , children aged between 6 and 11, and children aged between 12 and 15. Model 2b adds the effect of coresiding grandparents on migration duration by children's age. Model 3 further distinguishes the gender of children for the three age-groups. The last two columns provide separate estimates for men and for women using the specification of Model 3.

As explained in the methodological section, it is very plausible that there are unobserved individual characteristics, such as motivation or ability, which affect the length

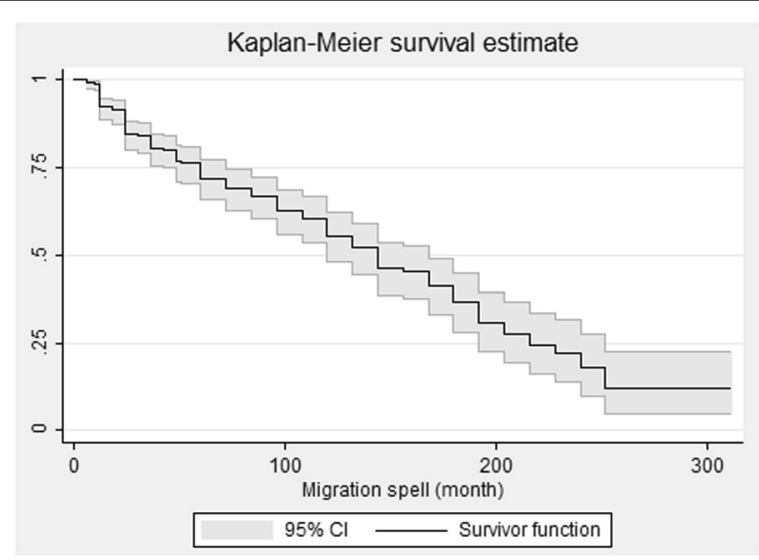

Figure 1 Kaplan-Meier survival estimate. 
Table 3 Hazard model estimates of migration duration

\begin{tabular}{|c|c|c|c|c|c|c|}
\hline & Model 1 & Model 2 & Model 2b & Model 3 & Men & Women \\
\hline \multirow[t]{2}{*}{ Baseline hazard (log spell month identifier) } & $0.569^{* *}$ & $0.684^{* * *}$ & $0.638^{* * *}$ & $0.549^{* *}$ & $0.344^{* * *}$ & $0.522^{* * *}$ \\
\hline & $(0.017)$ & $(0.004)$ & $(0.009)$ & $(0.032)$ & $(0.009)$ & $(0.003)$ \\
\hline \multirow[t]{2}{*}{ Age at first migration (years) } & $0.0512^{* *}$ & $0.0643^{* * *}$ & $0.0588^{* * *}$ & $0.0531^{* *}$ & $0.0408^{* *}$ & 0.0208 \\
\hline & $(0.016)$ & $(0.004)$ & $(0.008)$ & $(0.030)$ & $(0.020)$ & $(0.326)$ \\
\hline \multirow[t]{2}{*}{ Female } & $0.982^{* * *}$ & $1.125^{* * *}$ & $1.133^{* * *}$ & $1.036^{* * *}$ & & \\
\hline & $(0.001)$ & $(0.000)$ & $(0.000)$ & $(0.002)$ & & \\
\hline \multirow[t]{2}{*}{ Education (years) } & 0.0398 & 0.0501 & 0.0406 & 0.0354 & -0.00538 & 0.0489 \\
\hline & $(0.356)$ & $(0.284)$ & $(0.364)$ & $(0.426)$ & $(0.907)$ & $(0.443)$ \\
\hline \multirow[t]{2}{*}{ Married } & $1.223^{* *}$ & $1.345^{* *}$ & $1.221^{* *}$ & $1.081^{*}$ & 0.376 & $2.081^{* * *}$ \\
\hline & $(0.037)$ & $(0.019)$ & $(0.024)$ & $(0.073)$ & $(0.400)$ & $(0.002)$ \\
\hline \multirow[t]{2}{*}{ Occupation before return (wage worker $=1$ ) } & 0.0906 & 0.106 & 0.146 & 0.0257 & -0.239 & 0.691 \\
\hline & $(0.762)$ & $(0.744)$ & $(0.667)$ & $(0.930)$ & $(0.421)$ & $(0.140)$ \\
\hline \multirow[t]{2}{*}{ Working area before return (big city $=1$ ) } & 0.0365 & 0.0416 & 0.00725 & 0.00404 & -0.128 & -0.131 \\
\hline & $(0.886)$ & $(0.879)$ & $(0.977)$ & $(0.987)$ & $(0.626)$ & $(0.690)$ \\
\hline \multirow{2}{*}{$\begin{array}{l}\text { Log average rural per capita annual net } \\
\text { income (2004-2008) }\end{array}$} & $1.389^{* *}$ & $1.359^{*}$ & $1.841^{* * *}$ & $1.277^{* *}$ & 1.055 & 1.410 \\
\hline & $(0.030)$ & $(0.052)$ & $(0.006)$ & $(0.043)$ & $(0.118)$ & $(0.109)$ \\
\hline \multirow[t]{2}{*}{ Migrant spouse } & $-0.786^{*}$ & $-1.028^{* *}$ & $-0.833^{*}$ & -0.805 & $-0.497^{*}$ & $-0.967^{*}$ \\
\hline & $(0.088)$ & $(0.036)$ & $(0.072)$ & $(0.117)$ & $(0.084)$ & $(0.053)$ \\
\hline \multirow[t]{2}{*}{ Household size } & -0.112 & -0.0766 & 0.105 & -0.0486 & -0.0914 & 0.0937 \\
\hline & $(0.242)$ & $(0.483)$ & $(0.349)$ & $(0.636)$ & $(0.436)$ & $(0.562)$ \\
\hline \multirow[t]{2}{*}{ At least a member above 70} & -0.260 & -0.288 & $-0.582^{*}$ & -0.278 & -0.317 & -0.106 \\
\hline & $(0.426)$ & $(0.418)$ & $(0.095)$ & $(0.392)$ & $(0.422)$ & $(0.809)$ \\
\hline \multirow[t]{2}{*}{ At least a member aged 55 to 70} & -0.397 & $-0.573^{*}$ & & $-0.557^{* *}$ & -0.276 & $-1.244^{* * *}$ \\
\hline & $(0.150)$ & $(0.060)$ & & $(0.041)$ & $(0.369)$ & $(0.003)$ \\
\hline \multirow[t]{2}{*}{ At least one child $(<16)$} & $-0.736^{* *}$ & & & & & \\
\hline & $(0.021)$ & & & & & \\
\hline \multirow[t]{2}{*}{ At least one child (12-15) } & & -0.390 & -0.632 & & & \\
\hline & & $(0.292)$ & $(0.113)$ & & & \\
\hline \multirow[t]{2}{*}{ At least one child (6-11) } & & $-1.048^{* * *}$ & -0.173 & & & \\
\hline & & $(0.007)$ & $(0.630)$ & & & \\
\hline \multirow[t]{2}{*}{ At least one child $(<6)$} & & -0.164 & 0.283 & & & \\
\hline & & $(0.631)$ & $(0.475)$ & & & \\
\hline \multirow[t]{2}{*}{ Member aged $55-70^{*}$ child (12-15) } & & & 0.216 & & & \\
\hline & & & $(0.748)$ & & & \\
\hline \multirow[t]{2}{*}{ Member aged 55-70* child (6-11) } & & & $-3.610^{* * *}$ & & & \\
\hline & & & $(0.002)$ & & & \\
\hline \multirow[t]{2}{*}{ Member aged $55-70^{*}$ child $(<6)$} & & & $-1.223^{* *}$ & & & \\
\hline & & & $(0.023)$ & & & \\
\hline \multirow[t]{2}{*}{ At least a son (12-15) } & & & & -0.294 & -0.115 & 0.0677 \\
\hline & & & & $(0.474)$ & $(0.775)$ & $(0.914)$ \\
\hline \multirow[t]{2}{*}{ At least a daughter (12-15) } & & & & -0.524 & -0.498 & 0.354 \\
\hline & & & & $(0.275)$ & $(0.253)$ & $(0.670)$ \\
\hline \multirow[t]{2}{*}{ At least a son (6-11) } & & & & $-1.196^{* * *}$ & $-1.460^{* * *}$ & -0.237 \\
\hline & & & & $(0.006)$ & $(0.008)$ & $(0.662)$ \\
\hline
\end{tabular}


Table 3 Hazard model estimates of migration duration (Continued)

\begin{tabular}{|c|c|c|c|c|c|c|}
\hline \multirow[t]{2}{*}{ At least a daughter (6-11) } & & & & -0.369 & 0.00847 & -0.813 \\
\hline & & & & $(0.411)$ & (0.982) & $(0.190)$ \\
\hline \multirow[t]{2}{*}{ At least a son $(<6)$} & & & & 0.0476 & 0.176 & -0.195 \\
\hline & & & & $(0.900)$ & $(0.668)$ & $(0.757)$ \\
\hline \multirow[t]{2}{*}{ At least a daughter $(<6)$} & & & & -0.200 & -0.187 & -0.500 \\
\hline & & & & $(0.587)$ & $(0.640)$ & $(0.439)$ \\
\hline \multirow[t]{2}{*}{ Constant } & $-19.93^{* * *}$ & $-20.57^{* * *}$ & $-25.18^{* * *}$ & $-19.13^{* * *}$ & $-15.38^{* * *}$ & $-20.16^{* * *}$ \\
\hline & $(0.000)$ & $(0.001)$ & $(0.000)$ & $(0.001)$ & $(0.007)$ & $(0.005)$ \\
\hline Variance of gamma & 0.608 & 0.845 & 0.615 & 0.476 & & \\
\hline$L R$ test of variance of gamma $=0$ & 1.239 & 2.681 & 1.975 & 0.515 & & \\
\hline$p$-value & 0.133 & 0.051 & 0.080 & 0.236 & & \\
\hline Number of person-month observations & 22,986 & 22,986 & 22,986 & 22,986 & 16,154 & 6,832 \\
\hline Log likelihood & -740.3 & -738.0 & -726.2 & -736.5 & -444.7 & -283.6 \\
\hline
\end{tabular}

Source: Wuwei 2008 Survey.

Notes: See Table 2. p-values in parentheses. ${ }^{*} \mathrm{p}<0.10,{ }^{* *} \mathrm{p}<0.05,{ }^{* * *} \mathrm{p}<0.01$. The coefficients are estimated using the complementary log-log model with Gamma-distributed unobserved heterogeneity for columns 1 to 4 and with no unobserved heterogeneity for columns 5 and 6 . The coefficient on the duration dependence variable is the log of time.

of the migration spell. We thus estimate two different models: a complementary loglog model that does not take into account any unobserved individual heterogeneity (see Additional file 1: Table A1) and a complementary log-log model that assumes a Gamma distribution for an included individual heterogeneity term (Table 3). The LR test of the model with versus without unobserved heterogeneity reported at the bottom of Table 3 shows that the null hypothesis that the variance of the unobserved heterogeneity parameter is equal to zero is rejected for Models 1,2 , and $2 \mathrm{~b}$ (but not for Model 3), which implies that the model with Gamma-unobserved heterogeneity fits the data best for these models. Still, one can note that the corresponding estimations without controlling for unobserved heterogeneity presented in Additional file 1: Table A1 in the Appendix show fairly robust results. In all the models, the coefficients and their level of significance are broadly similar. The coefficients are slightly larger in absolute value when controlling for unobserved heterogeneity, which is consistent with the fact that failing to account for unobserved individual heterogeneity underestimates the extent to which the hazard rate increases with duration and the magnitude of the impact of the covariates on the hazard rate (Lancaster, 1990).

The various models displayed in Table 3 highlight a number of interesting patterns about the influence of left-behind children on parental migration duration. First, the effect of having children under 16 is negative and significant (Model 1): at each survival time, migrants with children have a $48 \%$ lower probability of returning (i.e., exhibit longer migration spells) than migrants with no child ${ }^{20}$. Model 2 shows that the negative impact found in Model 1 is attributable to children aged 6 to 11 (i.e., children in primary school), whereas the effect of pre-school children (under the age of 6) and children in secondary school (aged between 12 and 15) is negligible. Consistent with our expectation, having coresiding grandparents aged between 55 and 70 attenuates the parental time effect for children both under the age of 6 and between 6 and 11, as indicated in Model 2b. Interestingly, the effect seems stronger for children in primary school. The coefficient for having 
a child in primary school becomes small and insignificant, which suggests that the income effect related motive for the migrant to stay longer in the city dominates only when there is a rather young grandparent (aged between 55 and 70) at home.

Model 3 further distinguishes children of different age groups by gender and shows that the gender of the offspring also matters. Interestingly, the negative impact of children aged 6 to 11 can be specifically attributed to sons (and not significantly to daughters). Model 3 shows that having a son in primary school decreases the probability of return by $30 \%$. To investigate gender differences in return behaviour, separate estimations for men and for women are also reported in the last two columns of Table 3. Interestingly, they indicate that the son-in-primary-school effect is prominent for migrant fathers and nonsignificant for migrant mothers. In contrast, the impact of having grandparents at home (members between 55 and 70) only matters for women's return, indicating that grandparents are potentially good substitutes for mothers in the household for child care.

The main results regarding the impact of left-behind children on migration duration can be summarised as follows. First, individual migration duration is driven by family motives, with left-behind children-in particular children in primary school-being significant determinants of the migrants' decision to extend their length of stay in cities. Second, coresiding grandparents offer substitutes that allow for delayed return of migrant parents, particularly for those having young children (below the age of 12). Third, the gender of the left-behind child matters for the migration spell, with sons generating a significant impact compared to daughters. Fourth, there are also genderbased differences regarding the migrant parent: sons in primary school are a strong motivation for a longer length of stay of their migrant father, whereas grandparents appear as potential substitutes for mothers in taking care of left-behind children.

Going back to the illustrative model presented in Section 3, these findings highlight a number of potentially important channels in migrants' decision to stay longer in cities or to return. First, there is evidence that children at different ages matter differently in the decision-making of migrant parents. Second, the financial accumulation motive is a strong determinant of longer stay in cities for migrant parents having school-age children. At the same time, coresiding grandparents may attenuate the parental time effect, notably for migrant mothers, for both pre-school children and children in elementary school. Finally, some evidence of gender differences is found, which may be interpreted as illustrative of the traditional "son preference" values in rural China. Fathers tend to stay longer in cities if they have a son in primary school, but not if they have a daughter in primary school: we may conjecture that this difference reflects a stronger weight put on accumulating financial savings in order to keep their son at school (and to afford paying school fees at the secondary and post-secondary levels) in the foreseen future ${ }^{21}$.

In addition to children-related variables, we find consistent results regarding other explanatory variables in all the models. Unsurprisingly, the baseline hazard increases with elapsed survival time, which means that return probabilities depend positively on the length of migration spells to date. The increasing baseline can be interpreted as an illustration of the temporary nature of the migration phenomenon in China. To further illustrate this point, Figure 2 displays the predicted hazard rate at the mean of covariates based on the estimation of Model $1^{22}$. It shows that the predicted hazard rate is increasing all along the migration duration. 


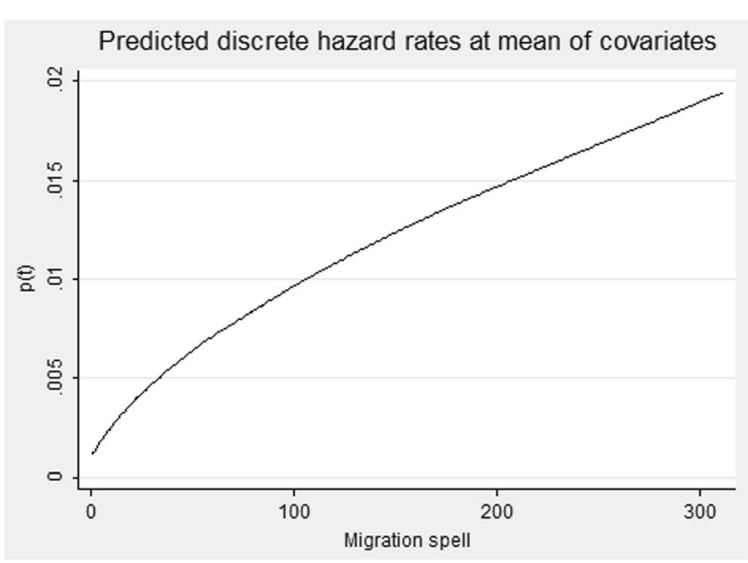

Figure 2 Predicted discrete hazard rates.

Economic conditions in the source region are found to have a positive and significant impact on the hazard rate: favourable economic conditions contribute to attracting migrants back home. In other words, the migration duration is longer for migrants from poorer regions than for migrants from wealthier emigration regions ${ }^{23}$.

Turning to individual characteristics, we find a positive impact of age on the hazard of return. People who migrated at an older age are more likely to have higher hazard rates of return. Gender also influences the length of migration, with female migrants being significantly more likely to have shorter lengths of stay than male migrants. Compared with single individuals, married individuals are also more likely to return quickly. Regarding the migration status of the spouse, migrants with a migrant spouse exhibit lower hazard rates, which means that they are less likely to return sooner than migrants who have a non-migrant spouse. This finding is consistent with Connelly et al. (2012), who find that for women, having a husband who has migrated increases the length of the last completed migration episode by eight months. One should note that the migration status of the spouse is likely to be endogenous because migration and the length of stay in city are household-level decisions. Hence, unobserved factors that are related to the spouse's decision to migrate may at the same time influence the migrants' return plans. However, the limitation of our cross-section dataset does not allow us to adequately instrument this variable. As a simple sensitivity check, Additional file 1: Table A1 displays estimates of Model 3 without the migration status of the spouse (Model 3b) and confirms the stability of our estimates. Finally, the effect of having elderly above the age of 70 in the household is negligible. As these elderly may be great grandparents in our sample, these findings may suggest that older (possibly great) grandparents are usually not the direct dependents of their grandchildren (the migrant parents here) and that they are not responsible for taking care of their great grandchildren.

\section{Conclusion}

This paper contributes to the understanding of migration dynamics within China by exploring the determinants of the spell of rural-to-urban migration and by highlighting the cost of leaving behind children. A simple model based on Dustmann (2003) is 
proposed to account for left-behind children through altruistic parents' concerns about the prospects of their offspring and to discuss the potential differentiated impact by age and gender.

Our empirical test confirms the role that left-behind children play in influencing migration duration in China. In particular, we find that having children of school-age is a motivation for migrant parents to extend their length of stay in the city, a result we interpret as illustrating the need for migrant parents to accumulate money for their offspring's education. In contrast, parental time appears substitutable by coresiding grandparents who contribute to delay the parents' return, especially mothers, when they have pre-school children or children in primary school. Regarding gender differences, our findings confirm a pro-son bias: compared to daughters, migrant parents respond more closely to the relative importance of the sons' needs at school age.

As discussed in the introduction, one of the key issues regarding migration duration in China lies in the prevailing non-voluntary separation of migrants and their leftbehind children as a social consequence of the restrictions imposed by the hukou system and education policies. In particular, leaving behind school-age children in order to accumulate finance for children's education seems a priority family solution for migrants' family. But children undoubtedly also need physical and mental care from their parents. Therefore, a direct implication of our findings is that including migrant children in the local urban education system and allowing them to take higher education entrance exams in the places where they have attended schools would certainly contribute to opening choices for migrants to settle in cities. This would not necessarily entail a full reform of the hukou system but rather access to public services no longer being tied to the place of household registration.

By emphasising the importance of family demand factors in return migration, our findings also emphasise the multidimensional nature of migration. The simple "success" (NELM) or "failure" (Lewis, 1954; Todaro, 1969) dichotomy and the "double selection" theory (Borjas and Bratsberg, 1996) on return migration may not properly capture all the dimensions at stake in out-migration and return migration. In the case of China, where particular institutions impose strong constraints on individual or family choice, our findings point to the importance of accounting for both economic and noneconomic determinants of migration duration to analyse the dynamics of migration. As such, they contribute to the literature on migration by stressing the importance of using a family unit framework in modelling return migration decision mechanisms. Moreover, because internal migration is the main engine of urbanisation in China, understanding the factors that explain variations in migration duration is important for designing optimal migration and urban development policies.

\section{Endnotes}

${ }^{1}$ In Chinese statistics, migrant workers are persons working and living outside the town of their household registration for a period over six months. See Chan (2012).

${ }^{2}$ See Chan and Buckingham (2008) for a detailed description of the household registration system, both historically and in light of the recent waves of reform.

${ }^{3}$ The examination system is not uniform across China, and its implementation varies greatly at the provincial level. In 1987, the Shanghai municipality pioneered in 
designing its own university entrance examination. Since then, 16 provinces have set up an independent decision system. Recently, the trend has been reversed, and it has been officially announced that 25 provinces and municipalities will adopt a unified national examination in 2016.

${ }^{4}$ See Antman (2013) for a survey of the growing empirical literature on the impact of migration on families left behind.

${ }^{5}$ One may yet refer to Carrión-Flores (2006), Djajic (2008), Dustmann and Kirchkamp (2002), Dustmann (2003), Kirdar (2013), Lindstrom (1996), Schroll (2009) and Stark et al. (1997).

${ }^{6}$ Wuwei county is not a special case within the province. In Connelly et al. (2012), among respondents of a survey of rural women of childbearing age from Anhui and Sichuan provinces collected in the fall of 2000 , only $12 \%$ took their child with them during their last migration episode. Clearly, a large number of children are being raised in rural areas by grandparents and relatives while their parents work in cities. An investigation conducted by the County Women's Federation in Hedian town (one of the 23 towns of the county) showed that $65 \%$ of the students at school in the town are leftbehind children. Among them, $77 \%$ have both parents away. In $43 \%$ of the cases, grandparents are taking care of the left-behind child, and in the other 57\%, relatives or friends are taking care of the left-behind child. The frequency of the parents' visits are once a year for $58 \%$ of the cases, once every two years for $27 \%$, and less than once every two years for $15 \%$.

${ }^{7}$ http://ah.anhuinews.com/system/2012/03/02/004806735.shtml (In Chinese).

${ }^{8}$ Either the main respondent (usually the household head or the spouse) or another family member was asked to answer individual questions for the absent on-going migrant member.

${ }^{9}$ In some instances, parents even reported returning "for the sake of children's education because of the hukou".

${ }^{10}$ This average duration of migration is consistent with the findings of larger urbanbased migrant surveys, including the 2007 RUMiCI survey, which reports an average duration of 7 to 8 years for on-going migrants. See Gong et al. (2008) for a comparison of all survey data available for China.

${ }^{11}$ The correlation coefficients are -0.65 for the whole population, -0.95 for outmigrants, and -0.52 for return migrants. All the correlations are statistically significant at 1 per cent.

${ }^{12}$ All children-related variables are computed at the moment of return for return migrants and at the time of the survey (2008) for on-going migrants.

${ }^{13}$ Considering the household, rather than the individual, as the most appropriate decision-making unit in return migration is consistent with the "New Economics of Labor Migration" (NELM) literature, which explicitly integrates migration decisions into a household strategy (Taylor, 1999).

${ }^{14}$ See, e.g., Lee (2008) for a review of the long history of pro-son bias in China.

${ }^{15}$ When the duration time is discrete, the estimation function is slightly different. A detailed description can be found in Jenkins (2008).

${ }^{16}$ The general idea of a proportional hazard model is that the effect of an independent variable is seen as having a constant proportional effect on the baseline hazard. The adoption of such a model is usually grounded on two important specifications: the 
distributional assumptions regarding the baseline hazard and the assumption of unobserved heterogeneity (Bhat, 1996).

${ }^{17}$ The most commonly used form in continuous-time duration studies is a parametric hazard (Bhat, 1996) with an assumed Weibull form baseline (Meyer, 1990).

${ }^{18}$ The age variable is recomputed to reflect the age at the moment of migration.

${ }^{19}$ However, one should note that for this long duration, the $95 \%$ confidence interval gives a range between $5 \%$ and $23 \%$. This might be related to the fact that we do not have many individuals with such a long migration history.

${ }^{20}$ This is calculated from the exponentiated coefficient (not reported here), which gives the hazard ratios as in a continuous time model.

${ }^{21}$ As rightly pointed out by the referee, it is interesting to note that the educational investment in sons translates into the fathers being away a good deal of the time while they are children, and this may be an issue later for boys not having their fathers around. In the end, the son preference may somehow backfire.

${ }^{22}$ The predicted hazard rate is calculated based on the mean level of the predicted hazard rate for each person given the values of her covariates and the spell month value (Jenkins, 2008).

${ }^{23}$ This finding is consistent with the international migration duration literature, particularly with the empirical findings of Schroll (2009) in the case of Denmark.

\section{Additional file}

Additional file 1: Table A1. Hazard model estimates with no unobserved heterogeneity.

\section{Competing interest}

The IZA Journal of Migration is committed to the IZA Guiding Principles of Research Integrity. The authors declare that they have observed these principles.

\section{Acknowledgement}

We gratefully acknowledge the financial support of the Région Rhône-Alpes (France) and the "Household Registration System Reform and Urban Population Management Innovation Study" Project of the Center for Modern Chinese City Studies (CCMC) at the East China Normal University. We are grateful to Ding Jihong for his precious help and advice, to Sun Zhongfeng and Anhui University for the helpful assistance on the survey, and to Wuwei local officials for their support and help during the fieldwork. We thank Tor Eriksson, Marc Gurgand, Hubert Jayet, Guy Lacroix, Yang Chengyu and a referee for their useful comments on earlier versions of the paper. Any remaining mistakes are our own. Responsible editor: Amelie Constant

\section{Author details}

${ }^{1}$ Université de Lyon, Lyon F-69007, France. ${ }^{2}$ CNRS, GATE Lyon St Etienne, 93, chemin des Mouilles Ecully, Lyon F-69130, France. ${ }^{3}$ IZA, Bonn, Germany. ${ }^{4}$ Business School, Beijing Normal University, No. 19 Xinjiekouwai Str., Haidian District, Beijing 100875, P.R. China.

Received: 25 November 2014 Accepted: 23 April 2015

Published online: 28 May 2015

\section{References}

Antman FM (2013) The impact of migration on family left behind. In: Constant AF, Zimmermann KF (eds) International Handbook of the Economics of Migration. Edward Elgar, Cheltenham, pp 293-308

Bhat CR (1996) A hazard-based duration model of shopping activity with nonparametric baseline specification and nonparametric control for unobserved heterogeneity. Transp Res B 30(3):189-207

Borjas GJ, Bratsberg B (1996) Who leaves? The out-migration of the foreign-born. Rev Econ Stat 78(1):165-176

Carrión-Flores CE (2006) What makes you go back home? Determinants of the duration of migration of Mexican immigrants in the United States. The University of Arizona, Mimeo

Chan KW, Buckingham W (2008) Is China abolishing the Hukou system? The China Quarterly 195:582-606

Chan KW (2012) Migration and development in China: Trends, geography and current issues. Migration and Development 1(2):187-205

Chen X, Huang Q, Rozelle S, Shi Y, Zhang L (2009) Effect of migration on children's educational performance in rural China. Comp Econ Stud 51:323-343 
Connelly R, Roberts K, Zheng Z (2012) The role of children in the migration decisions of rural Chinese women. Journal of Contemporary China 21(73):93-111

Djajic S (1989) Migrants in a guest-worker system. J Dev Econ 31:327-339

Djajic S (2008) Immigrant parents and children: an analysis of decision related to return migration. Rev Dev Econ 12(3):469-485

Djajic S, Milbourne R (1988) A general equilibrium model of guest-work migration-the source country perspective. J Int Econ 25:335-351

Dustmann C (2001) Why go back? Return motives of migrant workers. In: Djajic S (ed) International Migration: Trends, Policy and Economic Impact. Routledge, Abingdon, UK

Dustmann C (2003) Children and return migration. J Popul Econ 16:815-830

Dustmann C, Fadlon I, Weiss Y (2011) Return migration, human capital accumulation and the brain drain. J Dev Econ 95:58-67

Dustmann C, Kirchkamp O (2002) The optimal migration duration and activity choice after re-migration. J Dev Econ 67:351-372

Fan CC, Sun M, Zheng S (2011) Migration and split households: a comparison of sole, couple, and family migrants in Beijing, China. Environment and Planning A 43:2164-2185

Festini F, de Martino M (2004) Twenty Five Years of the One-Child Family Policy in China. Journal of Epidemial Community Health 58:358-359

Gao Y, Li L, Kim J-H, Congdon N, Lau J \& Griffiths S (2010) The impact of parental migration on health status and health behaviours among left behind adolescent school children in China. BMC Public Health. 10(56). doi:10.1186/1471-2458-10-56

Giannelli GC, Mangiavacchi L (2010) Children's schooling and parental migration: Empirical evidence on the 'left-behind' generation in Albania. Labour 24:76-92

Gong X, Kong ST, Li S, Meng X (2008) Rural-urban migrants - A driving force for growth. In: Song L, Garnaut R, Woo WT (eds) China's Dilemma, Economic Growth, the Environment and Climate Change. Asian Pacific Press and Washington D.C. Brookings Institution Press, Canberra

Hardee-Cleaveland K, Banister J (1988) Fertility policy and implementation in China, 1986-1988. Popul Dev Rev 14(2):245-286

Jenkins, SP (2008) Survival analysis with Stata, University of Essex course material available online at http:// www.iser.essex.ac.uk/survival-analysis (permanent URL).

Kirdar MG (2013) Source country characteristics and immigrants' migration duration and savings decisions, IZA Journal of Migration. 2013;2:8. doi:10.1186/2193-9039-2-8.

Kong T, Meng X (2010) The educational and health outcomes of the children of migrants. In: Meng X, Manning C, Effendi T, Li S (eds) The great migration: rural-urban migration in China and Indonesia. Edward Elgar Publishing, United Kingdom

Lai Z, Chen YP (2010) The educational consequences of migration for children in China. In G Liu, S Zhang \& Z Zhang (ed) Investing in human capital for economic development in China. World Scientific Publishing, Singapore

Lancaster T (1990) The Econometric Analysis of Transition Data. Cambridge University Press, Cambridge

Lee DY (2008) Do families spend more on boys than on girls? Empirical evidence from rural China. China Econ Rev 19(1):80-100

Lee MH (2011) Migration and children's welfare in China: The schooling and health of children left behind. The Journal of Developing Areas 44(2):165-182

Lewis WA (1954) Economic development with unlimited supplies of labour. Manch Sch 22(2):139-191

Lindstrom DP (1996) Economic opportunity in Mexico and return migration from the United States. Demography 33(3):357-374

Lu Y (2012) Education of Children Left Behind in Rural China. J Marriage Fam 74(2):328-341

McElroy M, Yang DT (2000) Carrots and Sticks: Fertility Effects of China's Population Policies. Am Econ Rev 90(2):389-392

McKenzie D, Rapoport H (2011) Can migration reduce educational attainment? Evidence from Mexico. J Popul Econ 24(4):1331-1358

Meyer BD (1990) Unemployment insurance and unemployment spells. Econometrica 58:775-782

Meyerhoefer CD, Chen CJ (2011) The effect of parental labor migration on children's educational progress in rural China. Rev Econ Househ 9(3):379-396

Michelson E (2010) Family Planning Enforcement in Rural China: Enduring State-Society Conflict? In: Oi JC, Rozelle S, Zhou X (eds) Growing Pains: Tensions and Opportunity in China's Transformation. Shorenstein Asia Pacific Research Center, Stanford, CA

Mu R, de Brauw A (2015) Migration and Young Child Nutrition: Evidence from Rural China. Journal of Population Economics. J Popul Econ 28:631-657

Prentice RL, Gloeckler L (1978) Regression analysis of grouped survival data with application to breast cancer data. Biometrics 34:57-67

Rossi A (2008) The impact of migration on children in developing countries. Unpublished manuscript prepared for the Youth Migration Conference. 24-26 April. Bellagio, Italy. globalnetwork.princeton.edu/bellagio/Rossi.pdf.

Schroll, S. (2009) Emigration of immigrants-a duration analysis, The Rockwool Foundation Research Unit and University Press of Southern Denmark, Stury Paper No.24.

Stark O, Helmenstein C, Yegorov Y (1997) Migrants' savings, purchasing power parity, and the optimal duration of migration. Int Tax Public Financ 4:307-324

Taylor JE (1999) The New Economics of Labour Migration and the role of remittances in the migration process. Int Migr 37(1):63-88

Todaro MP (1969) A model of labor migration and urban unemployment in less developed countries. Am Econ Rev 59(1):138-148

UNICEF (2014) What census data can tell us about children in China - Facts and Figures 2013, Beijing: UNICEF China. Available at: http://www.unicef.cn/en/uploadfile/2014/1110/20141110052120900.pdf. 
Wang SX (2014) The Effect of Parental Migration on the Educational Attainment of Their Left-behind Children in Rural China. The B.E. Journal of Economic Analysis and Policy 14(3):1037-1080

Wuwei County Government (2007) Report on enterprises establishment of return migrants in Wuwei County (in Chinese). Internal report of the Wuwei County Government

Xu WM, Tang JL, Wu D, Xu XY, Yang L (2007) Anhui nongcun liushou ertong xingwei wenti xianzhuang [Research on present situation of behaviour disorders of left-behind children in the countryside of Anhui province]. Journal of Applied Clinical Pediatrics (Shiyong ertong linchuang zazhi) 22(11):852-853, In Chinese

Zeng Z, Xie Y (2014) The Effects of Grandparents on Children's Schooling: Evidence From Rural China. Demography 51(2):599-617

Zhang H, Behrman JR, Fan CS, Wei X, Zhang J (2014) Does Parental Absence Reduce Cognitive Achievements? Evidence from Rural China. J Dev Econ 111:181-195

Zhao Q, Yu X, Wang X, Glauben T (2014) The impact of parental migration on children's school performance in rural China. China Econ Rev 31:43-54

Zhou M, Murphy R, Tao R (2014) Effects of Parents' Migration on the Education of Children Left Behind in Rural China. Popul Dev Rev 40(2):273-292

\section{Submit your manuscript to a SpringerOpen ${ }^{\circ}$ journal and benefit from:}

- Convenient online submission

- Rigorous peer review

- Immediate publication on acceptance

- Open access: articles freely available online

- High visibility within the field

- Retaining the copyright to your article

Submit your next manuscript at $>$ springeropen.com 